\title{
15/16-Year-Old Students' Reasons for Choosing and Not Choosing Physics at a Level
}

\author{
Jennifer DeWitt ${ }^{1}$ (D) Louise Archer $^{1} \cdot$ Julie Moote $^{1}$
}

Received: 28 November 2017 / Accepted: 6 May 2018 / Published online: 5 June 2018

(C) The Author(s) 2018

\begin{abstract}
Participation in post-compulsory physics is a matter of longstanding concern from both economic and equity perspectives. In considering this issue, this study draws upon Bourdieu's theory of social practice, particularly notions of the 'cultural arbitrary', to explore what insights into post-compulsory physics choice might be provided by students who could have chosen physics, but did not, opting for other sciences instead. Utilising survey data from over 13,000 year 11 (ages 15/16) students in England, as well as qualitative interviews with 70 students of the same age, findings reinforce the key role of individual aspirations in subject choice. However, they also highlight the influence of the cultural arbitrary of physics (e.g. as difficult, masculine), which leads many students to conclude that physics is not 'for me' and hence choose other paths. This finding emphasises the entrenched nature of the challenges facing efforts to increase equity in post-compulsory physics participation.
\end{abstract}

Keywords Cultural arbitrary · Equity · Participation · Subject choice

\section{Introduction}

Participation in post-compulsory physics is a matter of longstanding concern in a large number of Western, industrialised nations, due partly to its perceived key role in providing skills critical to economic growth (American Association of University

Jennifer DeWitt

j.dewitt@ucl.ac.uk

Louise Archer

1.archer@ucl.ac.uk

Julie Moote

j.moote@ucl.ac.uk

1 Education, Practice, \& Society, UCL Institute of Education, University College London, 20

Bedford Way, London WC1H 0AL, UK 
Women [AAUW], 2010; Boe, Henriksen, Lyons \& Schreiner, 2011; Department for Business, Enterprise and Skills [BEIS], 2017; Institute of Mechanical Engineers, 2016). The proportion of students studying physics at $\mathrm{A} \mathrm{level}^{1}$ (advanced level) in the UK, for instance, is noticeably lower than those studying other sciences and is also overwhelmingly male (Joint Council for Qualifications [JCQ], 2016). The low uptake of physics, particularly by females, also has implications for equity, as it can be a valuable route to prestigious, respected and well-paid careers.

In considering factors that support and hinder uptake of post-compulsory physics, we drew upon survey and interview data collected as part of a larger study. In analysing this data set, we became aware of a group of students who had chosen biology and chemistry (and often mathematics as well), but not physics for A level. Many of these students presumably could have studied physics but chose not to do so. ${ }^{2}$ The nature of our data set allowed us to compare this group with students who have elected to pursue physics at A level. In so doing, our analyses add to the limited work (e.g. Rodd, Mujtaba \& Reiss, 2014) that has been done in this area, as well as bringing a different sociological theoretical lens, described subsequently.

\section{Students' Choice (or Not) of Physics}

A number of studies have explored the reasons behind students' choices around postcompulsory education, particularly with regard to physics, as well as other sciences. Although they approach the problem from a variety of perspectives and were conducted in different locations, they flag up remarkable consistency in terms of students' reasons for their choices. Across multiple studies, a combination of interest/enjoyment as well as perceived utility emerge as key factors driving choice of subjects, including physics (Boe, 2012; Boe \& Henriksen, 2013). For females in particular, extrinsic motivationsuch as usefulness for desired university courses and/or careers - emerged as the most important factor driving intention to participate in post-compulsory physics (Mujtaba \& Reiss, 2013a, 2013b, 2014).

Whilst perception of usefulness for a desired career has a major influence on subject choice - and not just of physics (Vidal Rodeiro, 2007), it would it would seem that other aspects of the image of physics would also play a role, either directly or indirectly. For instance, multiple studies have highlighted that physics is considered to be a difficult subject in a range of countries (e.g. Carlone, 2004; Kessels, Rau \& Hannover, 2006; Krogh \& Thomsen, 2005). Other work has reflected that physics is perceived as less useful or relevant to daily life and/or future plans compared with biology, particularly by girls (Murphy \& Whitelegg, 2006).

It is also clear that physics is overwhelmingly masculine, with physics courses at A level and university being predominantly comprised of male students. Indeed, gender would seem to be the largest determinant (compared with prior attainment or type of school, for instance) of physics uptake at A level (Gill \& Bell, 2013). The masculine

\footnotetext{
${ }^{1}$ A level examinations are advanced academic qualifications that are taken when students are in their final year of secondary school in England and Wales. They are optional (some students pursue different qualifications) but required for university admission. Most students take A level examinations in three subjects.

${ }^{2}$ Our dataset does not allow us to analyse whether these students would have been allowed to choose A level physics or not. However, we argue that it is not an unreasonable assumption that many would have been able to do so, in terms of the required attainment in science.
} 
nature of physics is not 'lost' on students. For instance, compared with English, physics is associated with both masculinity and difficulty (e.g. Kessels et al., 2006).

In England, a review of several interventions which aimed to encourage uptake of post-compulsory physics, especially among girls, identified that the inclusion of material in lessons on careers in and from physics might be a particularly promising strategy (Daly, Grant \& Bultitude, 2009). However, this approach still begs the question as to how well the careers (including careers from physics) featured are aligned with students' actual aspirations. That is, if physics is not aligned with aspirations students hold, their intentions to pursue it would seem likely to be reduced considerably. Finally, in England, even those students who do perceive physics as personally relevant to them and their future plans face a number of systemic barriers to choosing the subject. In particular, in order to be allowed to choose post-compulsory physics, students are often required by their schools to attain particularly highly in science, more so than to choose other subjects.

\section{Conceptual Framing of Physics Choice}

In analysing this data set, we drew upon the work of Pierre Bourdieu to explore the question of why students who could choose physics do not. In particular, we draw on Bourdieu's theory of social reproduction, which proposes that it is the interaction of habitus and capital within field that produces practice (Bourdieu, 1984, 1990; Bourdieu $\&$ Passeron, 1990) and we consider subject choice as a form of practice. Bourdieu proposed the concept of habitus to refer to the layerings of dispositions that are produced through socialisation. We also use habitus as a conceptual tool for helping us understand how and why individuals come to see science - and physics in particular-as something that is 'for me' or 'not for me'. Our previous research using this conceptual tool has found that whether or not science is seen to be 'for me' is a critical factor in students' subject choice (Archer et al., 2012; Archer \& DeWitt, 2017).

We also draw on Bourdieu's notion of the 'cultural arbitrary' to help understand students' choice (or not) of physics. The cultural arbitrary refers to the way in which, through socialisation, people come to accept the legitimacy of the dominant culture and the elite position occupied by dominant groups. Education plays a key role in producing this acceptance of the cultural arbitrary, which is seen as 'natural' and self-evident (Bourdieu, 1984; Bourdieu \& Passeron, 1990). We suggest that the notion of the cultural arbitrary can be applied to the field of physics, to convey how the dominant culture of physics, whilst often experienced as being 'just how it is', is fundamentally an arbitrary construction that is perpetuated through ongoing socialisation and internalisation of dominant messages about what physics 'is' and who it is 'for'. For instance, our previous work (Archer, Moote, Francis, DeWitt, \& Yeomans, 2017) identified a dominant cultural arbitrary within physics as the widely taken-for-granted notion that physics is 'hard' or 'difficult', 'only for the brainy' and 'masculine'. This construction of physics is something, then, that young people must negotiate in order to choose the subject. That is, the strength of the cultural arbitrary lies in that it is accepted as 'the way things are' and leads to patterns of conformity (Jenkins, 2006).

In our analyses, we draw upon this notion of the cultural arbitrary to help us understand why a particular group of students ('Science - P') did not elect to take physics at A level. Looking through this lens, the research question we explore in this 
paper is as follows: what insights into subject choice around physics, if any, are provided by using the notion of the cultural arbitrary to explore the choices of students who could have chosen physics at A level, but did not?

\section{Methods}

The data used in this paper come from the ASPIRES project (https://www.ucl.ac. $\mathrm{uk} /$ ioe/departments-centres/departments/education-practice-and-society/aspires), a 10year study taking place in England. It is a mixed-methods, longitudinal investigation of children's science and career aspirations from ages 10-19, consisting of a quantitative online survey of the cohort and repeat (longitudinal) interviews with a smaller sample of students and their parents. This paper focuses on data collected when students were in year 11 (ages 15/16), a key year for students because although young people are required to continue in some form of education or training until the age of 18 in England, no subject or path is compulsory after age 16 (year 11). Consequently, students in year 11 are required to make decisions about their next steps, including which subjects to pursue at A level (if they elect to pursue advanced-level study).

Analyses that form the focus of this paper primarily focus on data from the survey, completed by over 13,000 students, which provide an overview of which students intend to pursue physics, as well as biology and chemistry, at A level and why. It also gives some broad indications about their perceptions of these subjects, as well as their aspirations. These analyses are supplemented by interview data, which provide richer insight into why some students did and did not choose physics and into how physics is perceived by these students, relative to other sciences.

\section{Instruments}

The survey was conducted online. It collected background data (e.g. gender, ethnicity, parental occupation) via multiple-choice questions and contained mainly Likert-type items on topics such as the following: aspirations (in science and generally); subject preferences; attitudes towards school science (differentiated where possible for physics, biology and chemistry); self-concept in science; images of scientists; participation in science-related activities outside of school; parental expectations; parental school involvement; parental attitudes towards science; and peer attitudes towards school and towards school science. The year 11 survey also included items about post-16 choices, career education and work experiences. The ASPIRES survey was initially developed by drawing on previously validated instruments (e.g. Barmby, Kind \& Jones, 2008) and extensively piloted. Reliability and validity analyses were used to further refine the survey. Details on the development and validation of the initial survey instrument have been described elsewhere (DeWitt et al., 2011).

Reliability and validity analyses were also carried out on the year 11 survey (the one reported on in this paper), using exploratory factor analyses (direct oblimin rotation) and Cronbach's alpha to determine the unidimensionality and internal consistency of the scales. The factor analysis revealed 12 resolvable components/factors overall, with Cronbach's alphas ranging from 0.657 to 0.927 , which are acceptable considering the numbers of items involved. Two of these components/factors were of interest to the current paper: 'aspirations 
in science and medicine' (Cronbach's alpha $=0.913$ ) and 'aspirations in engineering' (Cronbach's alpha $=0.657$ ). Please see the Appendix for the factor loadings of the items in these components.

The qualitative interviews explored broadly similar topics to the survey, including aspirations (and sources of these aspirations), interests in school and out, likes/dislikes about school, attitudes towards and engagement in school science, and broader perceptions and engagement with STEM subjects. Interviews lasted between $30 \mathrm{~min}$ and $1 \mathrm{~h}$ and were audio-recorded. Interviews were conducted by members of the project team, all of whom are white females (including academics, a $\mathrm{PhD}$ student and a research administrator). A complete copy of the survey and/or interview questions is available on request.

\section{Participants}

Over 13,000 students participated in the survey and were recruited from 340 secondary schools in England (296 state schools and 44 independent), including all regions of the country. The schools were comparable to the overall national distribution of schools in England in terms of attainment and proportion of students eligible for free school meals. Of the 13,421 students completing the survey, $46.7 \%$ were male and $53.3 \%$ were female. Ethnicity was self-reported, with the majority of students $(75.9 \%)$ categorising themselves as White. Other ethnicities included South Asian (9.7\%), Middle Eastern (0.9\%), Black (3.7\%), Chinese/East Asian (1.5\%) and Mixed/Other (4.8\%). A small proportion (3.4\%) of students elected not to answer this question.

The survey also included measures of social class and cultural capital. Parental occupation was used as a broad indicator of social class and students were assigned to the highest social class indicated by parental occupation (of the father or mother). ${ }^{3}$ Students came from a range of social class backgrounds, with nearly half $(48.9 \%)$ reporting having a parent in a professional or managerial occupation. A further $28.0 \%$ indicated a parent in a skilled occupation, $11.1 \%$ in a semi-skilled or unskilled occupation and $6.11 \%$ in some other job. In addition, $5.6 \%$ of students had parents who were homemakers, unemployed or had an unknown occupation.

With regard to cultural capital, we draw on Bourdieu (Bourdieu, 1984; Bourdieu \& Passeron, 1990; Bourdieu \& Wacquant, 1992), who conceptualised cultural capital as encompassing qualifications, dominant forms of knowledge and understanding and socially valued forms of 'taste'. In our survey, cultural capital was determined by responses to items such as parental education (e.g. university attendance), approximate number of books in the home and frequency of museum visitation. For simplicity, the scores were grouped into categories, with $5.5 \%$ of students having very low levels of cultural capital, $30.9 \%$ with low levels, $31.1 \%$ medium, $17.1 \%$ high and $15.4 \%$ very high levels of cultural capital.

As noted, the year 11 iteration of data collection also included qualitative interviews, which were conducted with 70 students (all of whom had been tracked since their final year of primary school, when they were 10/11). Respondents included 30 boys and 40

\footnotetext{
${ }^{3}$ Although questions related to parental occupation were extensively piloted over multiple rounds of the survey, they remained problematic for students. Consequently, we provide the distribution of those responses as a broad indicator of social class but do not include them in the analyses, due to ongoing concerns about the reliability of the measure.
} 
girls, who came from a broad range of socioeconomic classes and ethnic backgrounds: White British (20 male, 31 female), White European (1 male, 2 female), South Asian (4 male, 4 female) and Black African/Caribbean ( 2 male, 3 female), and mixed (3 male).

Interview participants were originally recruited from 11 schools across England, which were sampled from 279 schools that participated in the original (year 6) survey and reflected a range of school contexts and populations (e.g. 'multiethnic urban/inner city schools', 'working-class suburban'). Over the course of the project, students were tracked as they moved through to over 40 secondary schools. (Note that more precise information about the students of interest to our research question-both survey and interview participants - is included in the findings section.)

\section{Analyses}

Although the survey contained a range of questions, a smaller subset forms the focus of the analyses in this paper. In addition to background/demographic information on choosers and non-choosers of physics (as well as biology and chemistry), questions of particular interest to this analysis concern reasons students provide for their A level subject choices (e.g. the percentages agreeing with items such as 'How useful the subject is for my future job or career' or 'How much I enjoy the subject'); perceptions of science (e.g. which areas they find most interesting or difficult; how useful the different sciences are perceived to be); and information about their future aspirations (e.g. how many express an interest in pursuing science, engineering or other careers).

Initial quantitative analyses were primarily descriptive, in order to gain an overview of the groups of interest, namely, students who intended to choose physics at A level ('Science + P' students) and those who intended to choose biology and chemistry, but NOT physics, at A level ('Science - P' students). Next, chi-square tests were employed to examine group differences in demographics (e.g. gender, ethnicity), as well as to compare distribution of reasons given for A level choices. As these variables are categorical, cross-tabulation (chi-square) analyses were appropriate. Additionally, $t$ tests were performed to compare means of Science $+\mathrm{P}$ and Science $-\mathrm{P}$ students on composite variables ${ }^{4}$ of interest (such as science aspirations and engineering-related aspirations), an appropriate choice due to the continuous nature of the dependent variables. When referring to these analyses, percentages are reported and discussed, whilst any suggestions of inferences are supported by $t$ and chi-square values.

Interviews were transcribed and thematically organised using NVivo. For the purposes of this paper, we focused on questions related to post-16 subject choices (and reasons for those choices), aspirations and perceptions of physics and other sciences (chemistry and biology). In addition, due to the focus of our research question on students who chose physics and those who chose biology and chemistry but not physics, we restricted our analyses to those (24 out of 70) students. Analyses drew broadly on constant comparative analysis (Miles \& Huberman, 1994) and thematic analysis (Braun \& Clarke, 2006) techniques, in which multiple readings of the

\footnotetext{
${ }^{4}$ Principal components analyses identified a number of components in the survey data, including aspirations in science and engineering-related aspirations (as well as other components which do not address the research questions and are not included in this paper). The items comprising these components were scored (e.g. strongly disagree $=1$, disagree $=2$, strongly agree $=5$ ) and used to form composite variables.
} 
interview transcripts were performed in order to identify patterns or themes in the ways in which students responded to key questions (i.e. about reasons for their A level subject choices). More specifically, analysis began with a careful reading of the transcripts to develop initial codings of how participants were justifying their A level choices and how they seemed to perceive physics, particularly relative to other sciences. We then applied a theoretical lens to the transcripts, which drew our attention to ways in which elements of habitus and the cultural arbitrary of physics were manifested in what students had to say. We moved back and forth between the transcripts and notes and reflections on participants' responses in order to build up a schema of the types of justifications they provided and perceptions they seemed to hold about physics, which was also informed by our conceptual framework and Bourdieu's notion of the 'cultural arbitrary' in particular. This schema was, in turn, compared iteratively with the transcripts to confirm that it did capture the range of ways in which participants spoke, particularly about reasons for their choices. Themes were compared between the two groups of interest - Science $+\mathrm{P}$ students and Science $-\mathrm{P}$ students - to explore whether they differed in their reasons for their choices, in their perceptions of physics or in some other way. We were also able to explore whether these groups differed in other ways as well, such as in their aspirations.

Our analyses were limited, however, in that whilst they could provide a sense of the range of views expressed (and by whom), a more robust categorisation of students' views was prohibited by the nature of the data. That is, due to the semi-structured nature of the interviews, not all students were asked questions that would enable us to tease apart their perceptions of physics (e.g. as useful for jobs), relative to chemistry and biology. Nevertheless, the data do allow us to glean some sense of how the separate sciences were perceived by many of our participants and to provide a richer picture of those who do and do not choose physics (and their reasons for these choices), thus enhancing the findings emerging from the survey data.

\section{Findings}

We begin with an overview of the background characteristics of those who chose physics A level (Science + P students), comparing them with the other group of primary interest to our research question, i.e. Science $-\mathrm{P}$ students (those who intend to study biology and chemistry at A level, but not physics), in order to situate and provide context for the findings. We then move on to compare these groups in terms of their reasons for their A level choices and their aspirations, drawing primarily on survey data but illustrated by interview excerpts. Finally, we focus more closely on the interviews in order to explore differences between these groups in terms of their perceptions of physics, paying particular attention to the possible role of the cultural arbitrary of physics in these students' subject choices.

\section{Who Chooses Physics (and Chemistry and Biology)?}

In the survey, students were asked to select which subjects they intended to take at A level. Of the 9206 students who reported intending to pursue A level study at $16,42.1 \%$ were male and $57.9 \%$ were female. However, among Science $+\mathrm{P}$ students (those 
intending to study A level physics, $N=2143$ ), $64.7 \%$ were male and $35.3 \%$ were female. Put differently, $35.8 \%$ of boys were planning to study physics at A level but only $14.2 \%$ of girls were planning to do so, a highly significant difference $\left(\chi^{2}(1)=\right.$ $588.083, p<.0001)$. In contrast, the gender balance in the Science $-\mathrm{P}$ group (choosing both biology and chemistry but not physics, $N=1264$ ) was weighted in favour of females: $73.1 \%$ of this group were female but only $26.9 \%$ were male. In other words, $17.3 \%$ of girls but only $8.8 \%$ of boys planned to study biology and chemistry (but not physics) at A level, another highly significant difference $\left(\chi^{2}(1)=138.381, p<.0001\right)$.

Other than this gender imbalance, the backgrounds of students in the Science $-\mathrm{P}$ and Science $+\mathrm{P}$ groups were quite similar. ${ }^{5}$ For instance, in terms of ethnicity, higher proportions of Asian (28.5\%) and Middle Eastern (26.5\%) students report intending to study physics A levels, compared with students of Black $(21.9 \%)$ or White $(21.8 \%)$ ethnic backgrounds. Similar patterns were found in the Science $-\mathrm{P}$ group, where greater proportions of Asian (26.4\%) students, compared with White (11.5\%) students, opted to study these A levels (biology and chemistry). ${ }^{6}$ With regard to cultural capital, as students' cultural capital increases, so do their intentions to pursue physics: $28.3 \%$ of students with very high levels of cultural capital plan to study A level physics, whilst only $16.1 \%$ of students with low levels of cultural capital do. Likewise, $17.8 \%$ of students with very high cultural capital fall into the Science $-\mathrm{P}$ choosers group, whilst only $10.2 \%$ of students with low cultural capital do.

Overall, compared with the rest of the survey sample (and compared with all students intending to pursue A levels) students choosing physics A level would seem to be more likely to be male, Asian (or Middle Eastern) and have higher levels of cultural capital. They were also likely to report being in the top set (or attainment group) for science and have family members working in science. However, the differences in the background characteristics between Science $+\mathrm{P}$ and Science $-\mathrm{P}$ students are less pronounced, with the clear exception of gender. The reversal in terms of gender distribution between these groups is in alignment with national and international patterns of those studying physics and pursuing careers in the physical sciences.

A relatively similar pattern appeared among our qualitative sample. Of the 24 students who we focus on in this analysis (because they have chosen physics for A level, or biology and chemistry but not physics), 13 are Science $+\mathrm{P}$ and 11 are Science - P students. Overall, there were nine boys and 15 girls, but whilst gender was quite balanced in the Science $+\mathrm{P}$ group (six boys and seven girls), the Science $-\mathrm{P}$ group contained three boys and eight girls. These two groups were quite comparable in terms of attainment, ethnicity and social class backgrounds. Caution is warranted in drawing any generalisations from such a small sample but we find it interesting that the greater proportion of girls in the Science $-\mathrm{P}$ group does parallel our quantitative sample.

\section{Reasons for A Level Choices: Utility, Enjoyment and Attainment}

In both the survey and the interviews, students were asked about their reasons for their A level choices. On the survey, this was a closed-ended question, asking students to select their most important reasons for their choices. Across all students (including

\footnotetext{
${ }^{5}$ Because these differences were small and not statistically significant, inference tests are not presented.

${ }^{6} 19.7 \%$ of Black students and $16.9 \%$ of Middle Eastern students were in the Science - P group.
} 
Science $+\mathrm{P}$ and Science $-\mathrm{P}$ students), the most popular reason selected was 'how useful the subject is for my future job or career'. The proportions selecting this as their most important reason were $44.1 \%$ of Science $+\mathrm{P}$ and $52.7 \%$ of Science $-\mathrm{P}$ students (44.7\% all students intending to pursue A level study). The second most popular reason was enjoyment of the subject, with $19.9 \%$ of Science $+P$ choosers and $15.1 \%$ of Science $-\mathrm{P}$ choosers $(19.5 \%$ overall) providing this as their most important reason for their choices. Across both groups (and overall), 'to help me get into university' was the third most popular justification. Far fewer students reported subject attainment (how well they do), helping to keep options open, how well subjects go together or teachers as a reason for their A level choices.

Although their top three justifications are the same for both groups, the proportion of students selecting how useful the subject is for their future as their primary reason differs significantly between the Science $+\mathrm{P}$ and Science $-\mathrm{P}$ students $\left(\chi^{2}(1)=23.294\right.$, $p<.001)$. Similarly, the proportion of students selecting enjoyment as their primary justification for subject choice differs significantly between these two groups $\left(\chi^{2}(1)=\right.$ $12.411, p<.001)$. That is, Science $+\mathrm{P}$ students were more likely to report enjoyment and less likely to report usefulness as their primary justification for A level choice, compared with Science $-\mathrm{P}$ students (although, overall, both groups' most frequent justification was that of usefulness).

Similar patterns emerged from the interview data. Most students justified their A level plans in terms of their intended paths (related to job/career or to university), enjoyment of/interest in the subject, or both. This pattern held for Science $+\mathrm{P}$ and Science $-\mathrm{P}$ students alike.

Maths and physics I just chose them cos I enjoy those subjects... Because most sort of degrees or whatever just require maths and physics. (Bob, White upper middle class boy, Science + P)

I like biology as a subject, and I think to do something with medicine, I do need chemistry as well. And having said like about maths and physics but the main two they look for is biology and chemistry ... I'm not really that big of a fan of physics. (Rebecca, White middle class girl, Science $-\mathrm{P}$ )

Although attainment was rarely selected as a reason for A level choices on the survey, the interviews painted a more complex picture, with students also justifying their choices by referring to their achievement or aptitude in the subject, which they often also linked to enjoyment. That is, they talked about subjects they enjoyed and did well in.

It was kind of just like a mixture of that's what I enjoy and that's what I'm good at. I mean certainly for the three sciences it's kind of like well I enjoy all three, I'm kind of equally good at all three. (Davina, White upper middle class girl, Science + P)

\section{Physics as Necessary/Not Necessary for Future Aspirations}

Our interview and survey data alike reflect that aspirations (or perceived subject usefulness for them) are a key driver of subject choice. However, it would seem that 
general usefulness for 'many jobs' is not sufficient - it is perceived usefulness for and link to a desired future career that is key for many. Additionally, although Science $+\mathrm{P}$ students interviewed often mentioned enjoyment and interest as influencing their choices, it is noteworthy that 12 of the 13 expressed aspirations that were linked to this choice, with eight having either engineering or physics itself (cosmologist, astrophysicist) as an aspiration. Only one had aspirations (music producer or psychologist) that did not seem somehow related to physics and indeed, she dropped physics after the first year of post-compulsory study.

A different picture is painted by the aspirations of Science - P students. Although all 11 interviewed aspired to careers in medicine or another science (e.g. pharmaceutical research, forensic science, sports science), for these students, physics - whilst perhaps facilitating - is not required (or perceived to be required) for the paths they which to pursue. For instance, Joanne (White, middle class), an extremely high-attaining student, has always enjoyed and excelled in science and intends to pursue pharmaceutical research. However, physics is not necessary to gain admission onto the university courses in which she is most interested-including the prestigious Natural Sciences degree at Cambridge. Likewise, other students also articulated the way in which physics is not needed for careers such as medicine or forensic science.

Physics isn't actually quite needed for forensic (science)... but chemistry, biology and English is needed. (Vanessa, Black working class girl, Science $-\mathrm{P}$ )

So like to go down like that medicine route you sort of need the maths, biology, chemistry... (Colin, Asian lower middle class boy, Science - P)

Thus, it would seem that - with a few exceptions - a determining factor in whether students choose physics is its perceived direct link to, and necessity for, a desired career, particularly (though not exclusively) in engineering. Additional survey data around aspirations is also consistent with this: $56.3 \%$ of Science $+\mathrm{P}$ students agreed or strongly agreed that they would be interested in working in engineering, in contrast with only $22.2 \%$ of Science $-\mathrm{P}$ students. Moreover, on a composite variable reflecting aspirations in engineering (scale of 2-10), Science $+\mathrm{P}$ students had significantly higher scores $(M=6.72, \mathrm{SD}=2.12)$, compared with Science $-\mathrm{P}$ students, $(M=5.026, \mathrm{SD}=$ $1.95), t(2813.339)=23.595, p<.001$, Cohen's $d=0.83$. However, Science - P students had higher scores on a composite variable capturing 'aspirations in science and medicine' $(M=24.265, \mathrm{SD}=3.668)$ than Science $+\mathrm{P}$ students $(M=22.03, \mathrm{SD}=$ 4.88), $t(3195.211)=15.069, p<.001$, Cohen's $d=0.52$. Consistent with this, $86 \%$ of Science $-\mathrm{P}$ students expressed an interest in being a doctor/working in medicine and $86.2 \%$ agreed they would like to work in science. In contrast, $44.2 \%$ of Science $+P$ students were interested in working in medicine and $70.4 \%$ agreed they would like to work in science.

That Science $+\mathrm{P}$ students are likely to aspire to different kinds of careers is also reflected in that $24.4 \%$ claimed that 'creating things' was a very important reason for choosing a particular kind of work (compared with $15.1 \%$ of Science $-\mathrm{P}$ students). Likewise, only $40.4 \%$ of Science + P students felt that 'to help other people' was very important, in contrast with $61.4 \%$ of Science $-\mathrm{P}$ students. Overall, then, it would appear in many or most cases, Science $+\mathrm{P}$ students hold different aspirations from 
Science $-\mathrm{P}$ and it is the usefulness - or necessity - of physics for these desired future paths that is a driving factor motivating the decision to pursue the subject once it is no longer compulsory. Put differently, Science $+\mathrm{P}$ students appear to find the subject to be highly personally relevant, rather than simply valuable or useful in a broad sense.

\section{Perceptions of Physics: the Cultural Arbitrary at Work}

Whilst most students make their A level choices for more than a single reason, one of the key drivers of subject choice is clearly the perceived relationship between a subject and students' future plans. At the same time, whether physics is perceived as relevant to future plans seems potentially influenced by how it is constructed, leading to the question of whether there are fundamental differences in how physics choosers, compared with Science $-\mathrm{P}$ students, construct the subject. Previous research suggests that physics is often perceived as abstract and disproportionately difficult, compared with other sciences (Kessels et al., 2006; Krogh \& Thomsen, 2005; Murphy \& Whitelegg, 2006; Oon \& Subramaniam, 2013). Consequently, we explored our data for insight as to whether such perceptions were shared equally by Science $+\mathrm{P}$ and Science $-\mathrm{P}$ students. In doing so, we were particularly interested in whether these perceptions were aligned with the cultural arbitrary of physics as a 'hard' subject. (Note that as there are relatively few survey questions related to perceptions of physics, the analyses in this section rely almost exclusively on interview data.)

As we detail below, it appears that on the whole, Science $+\mathrm{P}$ and Science $-\mathrm{P}$ students do not have markedly different images of physics as a subject. Whist Science $-\mathrm{P}$ students do perceive it as abstract ('the abstractness of physics'; 'things you can't experience or see'), such abstractness is actually part of the appeal for some physics choosers:

With theoretical physics you can go like really complicated and just, like, you know, mind-blowing. (Davina, White upper middle class girl, Science + P)

Science $+\mathrm{P}$ and Science $-\mathrm{P}$ students alike are also well aware of the connection between maths and physics:

Physics is basically maths. (Bob, White upper middle class boy, Science $+\mathrm{P}$ )

I think it's because it's probably quite mathematical... so they [maths and physics] sort of go hand in hand (Football Master, White working class boy, Science - P)

In the case of students choosing physics A level, these characteristics do not seem to be problematic and they may even add to the appeal of the subject, whereas for some (though not all) Science - P students, they contribute to a lack of enjoyment:

The abstractness of physics - you've got to have a mind that can get around that and can understand those concepts, because most of it's based on concepts that you need to understand in the first place. (Joanne, White middle class girl, Science - P)

Additionally, the emphasis of physics on maths does not seem to be problematic in and of itself. Indeed, all but one of the Science $-\mathrm{P}$ students interviewed were also taking 
mathematics at A level. However, in the survey data, $75.8 \%$ of Science + P students agreed that maths is one of their best subjects, whilst this was the case for only $22.3 \%$ of Science $-\mathrm{P}$ students and whilst $64.2 \%$ of $+\mathrm{P}$ students feel they learn interesting things in maths lessons, only $54.2 \%$ of $-\mathrm{P}$ students do. One possibility is that whilst Science - P students may be 'all right' with maths, or are willing to choose it if they perceive it as sufficiently aligned with their goals, the maths incorporated into physics may be a step 'too far', contributing to their decision not to pursue physics.

What is also pervasive in the data is the cultural arbitrary of physics as a 'hard' subject. Indeed, although only $22.3 \%$ of Science $+\mathrm{P}$ students described physics as the area of science they found most difficult (in contrast with $73.3 \%$ of Science $-\mathrm{P}$ students), both groups of students were well aware of the reputation physics has as being a difficult subject:

Physics has always been seen as this intelligent and really hard... (Mienie, South Asian middle class girl, Science $+\mathrm{P}$ )

Loads of people have said to me compared to other subjects physics is really hard. (Kate, White upper middle class girl, Science $-\mathrm{P}$ )

Moreover, comments from some A level physics students even reflect a certain relish for the challenge of the subject. For instance, Tom4 (South Asian middle class boy) explained why he enjoyed physics by referring to its complexity: 'We were learning a lot more complex stuff and it was really nice to learn that'.

In contrast, the image of physics as a difficult subject seems to be more problematic for Science $-\mathrm{P}$ students, even though at times they struggled to articulate just why it was that they experienced it as difficult:

I really don't... um, I think it's the concepts are quite hard to grasp, all the, er, so I don't know, because in chemistry it's... then again chemistry is quite factual and so is physics, so I can't even say that, so I really don't know. I think I've just found it off putting. I don't know. (Isabel, South Asian upper middle class girl, Science - P)

There's just something about it that I don't really understand. I can't put my finger on it, though. (Football Master, White working class boy, Science-P)

This trouble in articulating what it is about physics that is difficult is emblematic of the cultural arbitrary, as something that is 'hard to put your finger on', due to it being socialised to be seen and accepted as 'just how things are'. Moreover, the image of physics as a hard subject - particularly relative to other sciences-does seem to influence the decision not to choose it at A level:

Physics is just physics, like no one really likes physics. ... Most people they just, they always seem to regret doing physics. Like I know of some year 13s who just don't... they're like 'Oh don't take physics, don't do it, it's just too much work and it's hard'. And then... yeah, physics is just the one thing you never hear good news from. So I think it's just passed on, like some type of rumour, and now everyone doesn't want to do physics. (Vanessa, Black working class girl, Science - P) 
Vanessa's comment above delineates the way in which perceptions (or the reputation) of physics can diffuse throughout a group of students, thus perpetuating the cultural arbitrary. For the most part, though, it seems that for the students choosing physics A level, a combination of interest in/enjoyment of the subject (including the appeal of the 'challenge' of it) as well as - for many - its link with aspirations means that they 'get on' well with the cultural arbitrary of physics. In contrast, for many of the Science $-\mathrm{P}$ students like Vanessa and her peers, this cultural arbitrary would seem to contribute to a sense of physics being 'not for them' and somehow 'other' and needing a 'certain kind of brain', as manifested in their struggles to articulate just what it is about physics that makes it difficult. They seem to be dissuaded by such characteristics, even when they are aware of the strategic value of the subject:

I feel like physics would be ... it would be the most useful cos there's not many people who pursue physics in college due to like the ongoing opinion that it's really hard, really like no one understands it. And I feel like if you did really like physics, then it would really get you somewhere... (Demi, White middle class girl, Science - P)

In this respect, we might argue that the data suggest that although these students appear to understand why/how physics is a high status and useful subject, these perceptions do not overcome their socialised dispositions and internalisation of the cultural arbitrary, through which they 'know' that they are, in the words of one student, 'not suited' to the subject or that physics is 'not for me'.

\section{Discussion}

These analyses have built upon previous research, particularly around perceptions of physics, subject choice and aspirations. In contrast with previous studies (e.g. Mujtaba $\&$ Reiss, 2013a, 2013b, 2014), our current analyses focused more precisely on the choices of students who could have chosen physics at A level, but did not. We argue that our focus on this group, using the lens of Bourdieu's theory of social reproduction and especially the notion of the cultural arbitrary, provides insights into subject choice and related equity issues surrounding participation in post-compulsory physics.

Our survey and interview data paint a consistent picture of subject choice as overwhelmingly driven by future plans related to jobs or university, a finding also aligned with previous international research (Boe \& Henriksen, 2013; Koul, Lerdpornkulrat \& Chantara, 2011; Mujtaba \& Reiss, 2013a, 2013b; Stokking, 2000). Our qualitative and quantitative data also converge on a shared construction of physics which is not only consistent with the cultural arbitrary of physics as difficult, but also that marks it out as linked with maths and distinct from other sciences, another finding echoing studies conducted internationally (e.g. Kessels, Rau \& Hannover; Oon \& Subramaniam, 2013). Where Science $+\mathrm{P}$ and Science $-\mathrm{P}$ students do differ is in how they situate themselves personally relative to physics. Our analyses identify the way in which, for some students, the cultural arbitrary of physics 'fits' with their habitus, whilst for others, it jars. Students who choose physics, then, may experience their dispositions (or habitus) and identity as being more closely aligned with the cultural arbitrary than those who elect not to take the subject. That is, their habitus is associated 
with high attainment and exceptionalness, making it well suited for a subject with a difficult and distinctive ('mind-blowing', according to Davina) image.

We argue that choosing physics (or any other subject) is an identity-related choice, related to deeply rooted dispositions as well as to aspirations. Although all students seem to recognise the cultural arbitrary of physics, some can more easily position themselves (and are comfortably positioned by others) within it, feeling it is 'for me' and choosing it at A level. In contrast, when students are generally 'okay' with physics - when they find it challenging but not overly onerous and consider it to be broadly useful as a subject - the downsides outweigh the benefits. Although the findings of this study confirm previous work (e.g. Mujtaba \& Reiss, 2013a, 2013b), reflecting that students who choose physics are deeply interested in the subject (including embracing the abstract/theoretical and mathematical side of it) and find it aligned with their habitus, often - though not always - via their aspirations, our Bourdieusianinformed analyses put in stark relief the cultural arbitrary of physics and the influence it has on the issue of low physics uptake.

\section{So, What Now?}

These findings do not paint a particularly optimistic picture for the future of physics. Whilst perhaps not surprising, they emphasise just how deep-seated the issue of equitable physics participation is and the way in which the cultural arbitrary makes it so difficult to shift. Simply 'making physics more interesting' or emphasising its general relevance to everyday life would seem insufficient to increase uptake, particularly by students from underrepresented groups, including females. Reducing the mathematics involved might be helpful but doing so would also risk hindering understanding of the content of the subject. Even highlighting its relevance or usefulness for a 'wide variety of jobs' would seem to be insufficient. Thus, there remains much work to be done to address perceptions - and choices - influenced by the cultural arbitrary of physics. Moreover, although the current study was conducted in the UK, research carried out in other countries (Boe \& Henriksen, 2013; Carlone, 2004; Kessels et al., 2006; Oon \& Subramaniam, 2013) suggests that the influence of the cultural arbitrary is likely to be equally strong elsewhere. Consequently, the issue of equitable participation in post-compulsory physics is likely to be similarly intractable elsewhere.

In the long term, we would like to argue for the democratisation of physics and dismantling its elite positioning. However, there are also actions, of varying scope and complexity, that could be implemented in the shorter term that might help more students, and more diverse students, come to experience physics as 'for them'. For example, in the UK, there are disproportionate grade requirements for entry into physics, compared with other subjects. Such a policy, in any educational system, not only restricts who is allowed to choose physics - ensuring that interest and effort alone are insufficient - but also powerfully reinforces the cultural arbitrary of physics as a 'hard' subject, which many students may thus perceive as 'not for me'. Of course, part of the rationale behind such a policy is the demanding nature of the physics A level syllabus. In turn, we argue for a re-examination of that syllabus, to explore how it might be re-structured to be more attainable and relevant for a wider range of students and to ensure that it is more comparable in how it is marked to other subjects at A level. Similar reflection and re-examination could be applied in other countries as well. 
We acknowledge that changes in school policy and exam requirements are quite long-term goals. More immediately, however, we propose making changes to the way science - and physics in particular - is taught and experienced in the classroom. In a sister project, Enterprising Science (https://www.ucl.ac.uk/ioe-sciencecapital), we have been developing a science capital pedagogical approach, which aims make student engagement and participation in science more equitable. This approach includes broadening what is recognised and valued in the science classroom, drawing on students' funds of knowledge (Gonzalez, Moll \& Amanti, 2005; Licona, 2013), or what they bring to the classroom. It involves going beyond contextualising, to personalising and localising the curriculum. Encouragingly, previous research suggests that proactively highlighting these personalised links could increase the uptake of postcompulsory physics (Bennett, Lubben \& Hampden-Thompson, 2013). At the same time, much remains to be done to make physics classrooms, and the subject more broadly (both within schools and as a whole), an equitable space. Ultimately, big changes are needed, not tweaks, if we are going to begin to shift the inequitable and declining uptake of physics and the cultural arbitrary that underpins and reinforces it.

Funding Information This work was supported by the Economic and Social Research Council [ES/ L002841/1].

Open Access This article is distributed under the terms of the Creative Commons Attribution 4.0 International License (http://creativecommons.org/licenses/by/4.0/), which permits unrestricted use, distribution, and reproduction in any medium, provided you give appropriate credit to the original author(s) and the source, provide a link to the Creative Commons license, and indicate if changes were made.

\section{Appendix}

Table 1 Factor loadings for survey components

\begin{tabular}{|c|c|c|c|}
\hline Component & Items & Factor loading & Score Range \\
\hline \multirow[t]{6}{*}{$\begin{array}{l}\text { Aspirations in science and } \\
\text { medicine }\end{array}$} & $\begin{array}{l}\text { I would like to study more science } \\
\text { in the future }\end{array}$ & 0.890 & \multirow[t]{6}{*}{$6-30$} \\
\hline & I would like to work in science & 0.858 & \\
\hline & I would like to become a scientist & 0.854 & \\
\hline & $\begin{array}{l}\text { I would like to be a doctor or work in } \\
\text { medicine }\end{array}$ & 0.661 & \\
\hline & $\begin{array}{l}\text { I would like to have a job that uses } \\
\text { science }\end{array}$ & 0.896 & \\
\hline & $\begin{array}{l}\text { I think I could be a good scientist one } \\
\text { day }\end{array}$ & 0.824 & \\
\hline \multirow{2}{*}{$\begin{array}{l}\text { Engineering-related } \\
\text { aspirations }\end{array}$} & I would like to be an inventor & 0.775 & \multirow[t]{2}{*}{$2-10$} \\
\hline & I would like to work in engineering & 0.586 & \\
\hline
\end{tabular}




\section{References}

Archer, L., \& DeWitt, J. (2017). Understanding young people's science aspirations: How students form ideas about 'becoming a scientist'. London, England: Routledge

Archer, L., DeWitt, J., Osborne, J., Dillon, J., Willis, B., \& Wong, B. (2012). Science aspirations and family habitus: How families shape children's identification and engagement with science. American Educational Research Journal, 49(5), 881-908.

Archer, L., Moote, J., Francis, B., DeWitt, J. \& Yeomans, L. (2017). The "exceptional" physics girl: A sociological analysis of multimethod data from young women aged 10-16 to explore gendered patterns of post-16 participation. American Educational Research Journal, 54(1), 88-126.

American Association of University Women. (2010). Why so few? Women in science, technology, engineering, and mathematics. Washington, DC: AAUW.

Barmby, P., Kind, P. M., \& Jones, K. (2008). Examining changing attitudes in secondary school science. International Journal of Science Education, 30(8), 1075-1093.

Bennett, J., Lubben, F., \& Hampden-Thompson, G. (2013). Schools that make a difference to post-compulsory uptake of physical science subjects: Some comparative case studies in England. International Journal of Science Education, 35(4), 663-689.

Boe, M. V. (2012). Science choices in Norwegian upper secondary school: What matters? Science Education, 96(1), 1-20.

Boe, M. V., \& Henriksen, E. K. (2013). Love it or leave it: Norwegian students' motivations and expectations for postcompulsory physics. Science Education, 97(4), 550-573.

Boe, M. V., Henriksen, E. K., Lyons, T., \& Schreiner, C. (2011). Participation in science and technology: Young people's achievement-related choices in late-modern societies. Studies in Science Education, 47(1), 37-72.

Bourdieu, P. (1984). Distinction: A social critique of the judgement of taste. Cambridge, MA: Harvard University Press.

Bourdieu, P. (1990). The logic of practice. Cambridge, England: Polity Press.

Bourdieu, P., \& Passeron, J. C. (1990). Reproduction in education, society and culture. London, England: Sage.

Bourdieu, P., \& Wacquant, L. (1992). An invitation to reflexive sociology. Chicago, IL: University of Chicago Press.

Braun, V., \& Clarke, V. (2006). Using thematic analysis in psychology. Qualitative Research in Psychology, $3(2), 77-101$.

Carlone, H. B. (2004). The cultural production of science in reform-based physics: Girls' access, participation, and resistance. Journal of Research in Science Teaching, 41(4), 392-414.

Daly, A., Grant, L., \& Bultitude, K. (2009). Girls into physics: Action research. London, England: Department for Children, Schools and Families.

Department for Business, Enterprise and Skills. (2017). Building our industrial strategy. London, England: BEIS.

DeWitt, J., Archer, L., Osborne, J., Dillon, J., Willis, B., \& Wong, B. (2011). High aspirations but low progression: The science aspirations-careers paradox among minority ethnic students. International Journal of Science and Mathematics Education, 9(2), 243-271.

Gill, T., \& Bell, J. F. (2013). What factors determine the uptake of A level physics? International Journal of Science Education, 35(5), 753-772.

Gonzalez, N., Moll, L. C., \& Amanti, C. (Eds.). (2005). Funds of knowledge: Theorizing practices in households, communities, and classrooms. Mahwah, NJ: Lawrence Erlbaum Associates.

Institute of Mechanical Engineers. (2016). Big ideas: The future of engineering in schools. London, England: Institute of Mechanical Engineers.

Jenkins, E. W. (2006). The student voice and school science education. Studies in Science Education, 42(1), 49-88.

Joint Council for Qualifications. (2016). Results 2016. Retrieved 3 May 2017 from http://www.jcq.org. uk/examination-results/A levels/2016.

Kessels, U., Rau, M., \& Hannover, B. (2006). What goes well with physics? Measuring and altering the image of science. British Journal of Educational Psychology, 76, 761-780.

Koul, R., Lerdpornkulrat, T., \& Chantara, S. (2011). Relationship between career aspirations and measures of motivation toward biology and physics, and the influence of gender. Journal of Science Education and Technology, 20(6), 761-770. 
Krogh, L. B., \& Thomsen, P. V. (2005). Studying students' attitudes towards science from a cultural perspective but with a quantitative methodology: Border crossing into the physics classroom. International Journal of Science Education, 27(3), 281-302.

Licona, M. M. (2013). Mexican and Mexican-American children's funds of knowledge as interventions into deficit thinking: Opportunities for praxis in science education. Cultural Studies of Science Education, $8(4), 859-872$.

Miles, M. B., \& Huberman, A. M. (1994). Qualitative data analysis: An expanded sourcebook. Newbury Park, CA: Sage.

Mujtaba, T., \& Reiss, M. J. (2013a). Inequality in experiences of physics education: Secondary school girls' and boys' perceptions of their physics education and intentions to continue with physics after the age of 16. International Journal of Science Education, 35(11), 1824-1845.

Mujtaba, T., \& Reiss, M. J. (2013b). What sort of girl wants to study physics after the age of 16 ? Findings from a large-scale UK survey. International Journal of Science Education, 35(17), 2979-2998.

Mujtaba, T., \& Reiss, M. J. (2014). A survey of psychological, motivational, family and perceptions of physics education factors that explain 15-year-old students' aspirations to study physics in post-compulsory English schools. International Journal of Science and Mathematics Education, 12(2), 371-393.

Murphy, P., \& Whitelegg, E. (2006). Girls in the physics classroom: A review of the research on the participation of girls in physics. London, England: Institute of Physics.

Oon, P.-T., \& Subramaniam, R. (2013). Factors influencing Singapore students' choice of physics as a tertiary field of study: A Rasch analysis. International Journal of Science Education, 34(1), 86-118.

Rodd, M., Mujtaba, T., \& Reiss, M. (2014). Qualified, but not choosing STEM at university: Unconscious influences on choice of study. Canadian Journal of Science, Mathematics and Technology Education, 14(4), 330-345.

Stokking, K. M. (2000). Predicting the choice of physics in secondary education. International Journal of Science Education, 22(12), 1261-1283.

Vidal Rodeiro, C. L. (2007). A level subject choice in England: Patterns of uptake and factors affecting subject preferences. Cambridge, England: University of Cambridge Local Examinations Syndicate. 